Full Length Article

\title{
Age-related changes in materialism in adults - A self-uncertainty perspective ${ }^{\text {it }}$
}

\author{
Christian Martin ${ }^{\mathrm{a}, *}$, Sandor Czellar ${ }^{\mathrm{b}}$, Mario Pandelaere ${ }^{\mathrm{c}, \mathrm{d}}$ \\ ${ }^{a}$ Maynooth University, Maynooth, Co. Kildare, Ireland \\ ${ }^{\mathrm{b}}$ Université de Lausanne, Quartier UNIL-Chamberonne, Bâtiment Anthropole, 1015 Lausanne, Switzerland \\ c Virginia Tech, 2016 Pamplin Hall, 880 West Campus Drive, Blacksburg VA 24061, USA \\ ${ }^{\mathrm{d}}$ Ghent University, Faculty of Economics and Business Administration, Tweekerkenstraat 2, 9000 Gent, Belgium
}

\section{A R T I C L E I N F O}

\section{Article history:}

Received 28 March 2018

Revised 9 August 2018

Accepted 19 September 2018

Available online 20 September 2018

\section{Keywords:}

Materialism

Age

Life span

Self-uncertainty

Self-concept clarity

Self-doubt

Self-esteem

\begin{abstract}
A B S T R A C T
Materialism is the focus of much research due to its negative consequences for individuals and societies. While recent research indicates that the strength of materialistic value orientations changes with age during adulthood, little is known about the processes that cause these age-related changes. We propose that changes in materialism, as people grow older, are rooted in changes in self-uncertainty. We find evidence for this idea in two studies and across different measures of self-uncertainty. In addition, we show that the changes in materialism cannot be explained by (age-related) differences in socio-demographic variables. Finally, our results indicate that changes in self-uncertainty provide a better account for changes in materialism than age-related changes in self-esteem.
\end{abstract}

(c) 2018 Elsevier Inc. All rights reserved.

\section{Introduction}

Materialistic values are a prominent values construct in different academic disciplines. The main reason for the interest in this concept is probably its relationship with different well-being indicators and a host of undesirable behaviors. For example, materialistic individuals seem to be less happy and less satisfied with their lives compared to their low-materialism counterparts (see Dittmar, Bond, Hurst, \& Kasser, 2014 for a meta-analysis). Similarly, materialism is related to decreased mental health (e.g., Muñiz-Velázquez, Gomez-Baya, \& Lopez-Casquete, 2017; Wang, Liu, Tan, \& Zheng, 2017) and compulsive buying (e.g., OteroLópez, Pol, Bolaño, \& Mariño, 2011; Otero-López \& Villardefrancos, 2013). Materialism is also negatively associated

\footnotetext{
is The reported studies were not pre-registered. Data for both studies was collected together with data for other projects. Since data analyses are still ongoing, the authors wish not to share the data. However, the authors will clearly indicate where future publications are based on the same datasets. CM designed both studies, collected and analyzed the data, and wrote the manuscript. SC provided feedback on the study designs and on the manuscript. MP provided feedback on the manuscript.

* Corresponding author.

E-mail addresses: Christian.Martin@mu.ie (C. Martin), Sandor.Czellar@unil.ch (S. Czellar), mpand@vt.edu, Mario.Pandelaere@ugent.be (M. Pandelaere).
}

with attitudes towards environmental protection (Hurst, Dittmar, Bond, \& Kasser, 2013) and might even interfere with the functioning of romantic relationships (Hui \& Tsang, 2017).

Given these undesirable consequences, it is not surprising that researchers have also studied the development and life span trajectory of materialism. Most of these studies have focused on changes during childhood. For example, the childhood family environment (e.g., Duh, 2016; Rindfleisch, Burroughs, \& Denton, 1997), parenting styles (Richins \& Chaplin, 2015), and children's exposure to advertisements (Opree, Buijzen, van Reijmersdal, \& Valkenburg, 2014) seem to influence the extent to which children develop a materialistic value orientation. Some research suggests that materialism also changes in adult life (Jaspers \& Pieters, 2016).

It is not clear, however, why the strength of materialistic tendencies changes over the course of adulthood. Several researchers have already recognized the need for more insights on this question (Jaspers \& Pieters, 2016; Wang \& Wallendorf, 2006). Yet, we are not aware of any research that directly addresses it.

The aim of the current research is to provide first insights into the processes that cause materialism to change in adults over time. We identify self-uncertainty as an important potential cause of materialism that changes as individuals mature. In two studies, we show that self-uncertainty can explain age-related changes in materialism, at least to some degree. We also investigate whether 
this process is robust by controlling for various socio-demographic variables that may be related to materialism and may also change over the course of an individual's life, such as income. Lastly, we investigate changes in self-esteem as an alternative potential account for changes in materialism. In sum, the present paper contributes to a developmental understanding of the materialism concept.

\subsection{Materialism and age}

In the last decades, materialism has been the focus of considerable research. While several definitions have been proposed (e.g., Belk, 1985; Shrum et al. 2013), we follow Richin's (2004) definition of materialism as "the importance ascribed to the ownership and acquisition of material goods in achieving major life goals or desired states" (Richins, 2004, p. 210). This construct is typically measured through three distinct facets or dimensions (Richins \& Dawson, 1992): The extent to which an individual defines his/her own and others' success in life via the possessions that a person owns (success dimension), the centrality of the acquisition of material possessions in a person's life (centrality dimension), and the pursuit of happiness through material acquisitions (happiness dimension).

Prior literature has mainly focused on the consequences (e.g., Dittmar et al., 2014; Hurst et al., 2013) and causes of materialism (e.g., Kasser, 2016; Kasser, Ryan, Couchman, \& Sheldon, 2004), but less research has examined how materialism develops over an individual's life span.

Extant research indicates that older adults tend to be less materialistic than younger adults, a finding that appears to hold across a wide range of countries. A negative relationship between age and materialism was found for example in Australia (Noguti \& Bokeyar, 2014), Germany (Müller et al., 2013), Israel (Ruvio, Somer, \& Rindfleisch, 2014), the UK (Dittmar, 2005), and the USA (Rindfleisch, Burroughs, \& Wong, 2009). A meta-analysis of these correlations reported an average correlation of $r=-0.16$ with noticeable differences in effect sizes between studies (Jaspers \& Pieters, 2016).

However, these age effects were usually only a tangential outcome of the respective studies and were not investigated further. Despite earlier calls for additional insights on the topic (Wang \& Wallendorf, 2006), researchers have only recently started to study the age-materialism relationship. One particular problem with the interpretation of age-related changes in cross-sectional data is that it is difficult to distinguish between age, cohort, and period effects (Yoon, Cole, \& Lee, 2009). In other words, cross-sectional data leaves unanswered whether materialism decreases as individuals grow older, whether individuals who are part of an earlier (later) birth cohort are less (more) materialistic, or whether certain large-scale changes in the societal or economic environment impact individuals' materialistic orientation.

Recent research suggests that all three types of effects (i.e., age, cohort, and period) may contribute to explaining age - materialism correlations. For example, Twenge and Kasser (2013) analyzed data from a nationwide survey of high school students in the US that was conducted every year since 1976 with participants of similar age (i.e., 12th graders) in each wave. They found evidence for generational shifts (i.e., cohort effects). The focus on materialistic goods and aspirations rose in pupils between 1976 and 1990. The level of materialism then declined marginally in the 1990s and stabilized at a relatively high level.

Kasser et al. (2014; Study 3) observed period effects. These authors measured materialism in Icelanders at different points in time while an economic crisis unfolded. The strength of materialism changed in these participants and these changes were attributed to changes in economic insecurity. These authors also reported a negative relation between age and materialism in another longitudinal study (Study 1) that, however, was subsequently not replicated (Study 2). Generally, Kasser et al. (2014) were interested mostly in the effects of materialism on well-being and did therefore not use their data to study in depth how materialism changes with age.

To our knowledge, the first and so far only comprehensive study of age-related changes in materialism in individuals was conducted by Jaspers and Pieters (2016). These authors analyzed a large-scale longitudinal dataset and were able to disentangle life cycle, period, and cohort effects in materialistic orientations in individuals. In their data, overall materialism exhibited a Ushaped trajectory across the life span. It decreases linearly until the age of 60 and starts to increase again afterwards. The acquisition centrality and possession-defined success dimensions had similar trajectories, while acquisition as the pursuit of happiness had a flat trajectory. Birth cohort effects were found for acquisition-centrality and possession-defined success, but not for acquisition as the pursuit of happiness. These authors also observed different main and interaction effects of an economic crisis (i.e., period effects) on some materialism dimensions. Overall, these results suggest that age effects are a composite of life cycle, birth cohort, and time-period variation in materialism in individuals. In addition, the age effects in materialism in their data were not explained by age-related changes in socio-demographic characteristics, such as income or employment status.

While these findings indicate how materialism changes with age, they are limited in explaining the mechanisms responsible for that change. This is especially the case with regard to the lifespan component of the age - materialism relationship as timeperiod effects could be attributed to economic crises (Jaspers \& Pieters, 2016; Kasser et al., 2014), and cohort effects to societal factors, such as exposure to advertising and job security (Twenge \& Kasser, 2013).

Chaplin and John (2007) found that the relationship between age and materialism is mediated by changing levels of selfesteem in children and adolescents. However, while studying young individuals in the phase when their materialistic values form is important (Goldberg, Gorn, Peracchio, \& Bamossy, 2003), it is unclear whether and to what extent these findings apply to adults. In addition, Chaplin and John (2007) use a measure that focuses on the role of material objects in the pursuit of happiness (i.e., the happiness dimension of materialism). It is therefore not clear to what extent these findings can be extended to other aspects of materialism.

Based on Chaplin and John's (2007) findings and on the observation that self-esteem trajectories over the life span are similar to materialism trajectories (Orth, Trzesniewski, \& Robins, 2010; Twenge, Carter, \& Campbell, 2017), it has been suggested that self-esteem might explain age-related changes in adults as well (Jaspers \& Pieters, 2016). This hypothesis, however, has not been tested and it is not clear whether self-esteem changes over the life span could potentially explain age effects in materialism in adults. While several studies reported a correlation between self-esteem and materialism (e.g., Richins \& Dawson, 1992), there is doubt as to whether such a relationship can actually be interpreted meaningfully. It has been suggested that self-esteem in itself may not be a direct predictor of materialistic tendencies. Rather, materialism might serve as a coping mechanism for individuals who experience a discrepancy between levels of implicit and explicit selfesteem (Park \& John, 2011). The present study therefore shifts focus from self-esteem to self-uncertainty as a possible mediating mechanism in the age - materialism relationship.

\subsection{Self-uncertainty as a mediating mechanism}

Self-uncertainty encompasses several different constructs (e.g., self-concept clarity, self-doubt, and self-esteem instability; De 
Cremer \& Sedikides, 2005). These different constructs are similar in that they constitute an individual's vagueness about one aspect of the self, such as one's competency or the content of one's selfconcept (Braslow, Guerrettaz, Arkin, \& Oleson, 2012). For example, self-concept clarity is defined as "the extent to which the contents of an individual's self-concept (e.g., perceived personal attributes) are clearly and confidently defined, internally consistent, and temporally stable" (Campbell et al., 1996, p. 141). Self-doubt is the "doubt about one's competence" (Oleson, Poehlmann, Yost, Lynch, \& Arkin, 2000, p. 491). Self-esteem instability is defined as "the degree to which self-esteem shows temporal fluctuations across relatively short periods" (Meier, Orth, Denissen, \& Kühnel, 2011, p. 604). While the different self-uncertainty constructs are distinct concepts, we follow De Cremer and Sedikides (2005) in treating them as different aspects of the same overarching construct.

Prior literature has indicated that self-uncertainty can cause people to turn to material objects to avoid contemplating this state of the self and the negative emotions that ensue (Reeves, Baker, \& Truluck, 2012). Indeed, materialism may allow people to build a sense of self and thus reduce feelings of self-uncertainty (Shrum et al., 2013). These ideas are supported by observed relationships between materialism and self-concept clarity (e.g., Noguti \& Bokeyar, 2014) and self-doubt (e.g., Christopher, Drummond, Jones, Marek, \& Therriault, 2006). Self-uncertainty thereby seems to be an antecedent of materialism (Chang \& Arkin, 2002).

Importantly, self-uncertainty seems to decrease with age through young adulthood and midlife. Several studies indicate that self-concept clarity increases as individuals mature (e.g., (Crocetti, Rubini, Branje, Koot, \& Meeus, 2016). Other types of self-uncertainty seem to have a similar relationship with age. Self-doubt decreases with age in different adult samples (e.g., Rindfleisch et al., 2009). The same seems to be true for self-esteem instability (Meier et al., 2011). Lodi-Smith and Roberts (2010) argue that this development can be explained by adults' increasing capability and resources to engage in meaningful identity-relevant roles through young adulthood and midlife. The level of self-uncertainty is thereby also tied to limitations to engage in roles, which might vary with age (Lodi-Smith \& Roberts, 2010; Lodi-Smith, Spain, Cologgi, and Roberts, 2017). In addition, Meier et al. (2011) suggest that self-uncertainty decreases with age because individuals possess increasing levels of acceptance of the own self (e.g., when failures occur), a decreased reliance on feedback from their social environment, and an increasing ability to avoid and cope with negative situations and life events. This is mirrored in relevant changes in personality characteristics over the life span (Meier et al., 2011).

\section{Theoretical model and overview of studies}

On the basis of the reviewed research, we propose that the relationship between age and materialism can be explained by agerelated changes in self-uncertainty. Our theoretical model is visualized in Fig. 1.

We test this model in two studies. In Study 1, we establish the role of self-uncertainty as a mediating construct in the age - materialism relationship. We used self-concept clarity as an operationalization of self-uncertainty in this study. In Study 2, we replicated this finding in a different sample, and using a second type of self-uncertainty (i.e., self-doubt) to establish that our model is not specific to self-concept clarity but holds for other types of self-uncertainty as well. In both studies, we control for sociodemographic characteristics and test if self-esteem is an additional mediating variable.

\section{Study 1}

The purpose of this study was to gather first evidence for the proposed theoretical model. In addition, we also investigated the robustness of the expected mediation process. For the latter purpose, we included several demographic factors that might vary with age and might be predictors of self-uncertainty and/or materialism as control variables in our models.

\subsection{Participants and procedure}

For this study, we recruited 429 participants on Amazon's Mturk. Two participants were excluded from the data analysis because they did not answer the scales seriously (i.e., participants provided the same answer to all items in the questionnaire, respectively in long segments of the questionnaire). The final sample consisted hence of 427 participants ( $52 \%$ male). The average age of our participants was 33.6 years $(\mathrm{SD}=12.3$ years; Range $=18-72$ years $)$. The median combined annual household income of our participants fell in the 30,000-39,999 USD bracket and 61\% of them had completed a college or professional degree. Sixteen percent of our participants were students, $65 \%$ employed or selfemployed, $2 \%$ retired, $15 \%$ were not currently officially employed (e.g., unemployed, homemaker), 2\% did not clearly indicate their occupation.

Data for this study was collected as part of a larger survey. The questionnaire was introduced as a survey of personality characteristics and informed consent was obtained. The questionnaire started with several unrelated measures. Then, materialism was measured using Richins' (2004) 15-item materialistic values scale (MVS). After an unrelated task, self-uncertainty was measured with Campbell et al.'s (1996) self-concept clarity scale (SCC). At the end of the questionnaire, Rosenberg's (1965) trait self-esteem measure (TSE), additional unrelated measures, and demographics were collected. The instructions before the individual difference measures were as follows: "On the next pages of this survey, you will find statements about different aspects of your life. There are no right or wrong answers. Different people have different personalities and none is better or worse than the other. They are just different. Please answer spontaneously and tick the answer that you feel best describes your personality."

Following Richins' (2004) recommendations, we calculated four indices based on the MVS items (i.e., a nine-item overall index, and indices for the success, centrality, and happiness sub-dimensions of materialism). The scores on the materialism measures ranged from 1 to 7 with Cronbach's alphas of $\alpha_{\text {overall }}=0.88, \alpha_{\text {success }}=0.84$, $\alpha_{\text {centrality }}=0.73$, and $\alpha_{\text {happiness }}=0.83$. Sample items are "The things I own say a lot about how well I'm doing in life" (success facet), "Buying things gives me a lot of pleasure" (centrality facet), "My life would be better if I owned certain things I don't have” (happiness facet).

To facilitate interpretation, SCC was reverse-coded to reflect self-uncertainty rather than self-certainty. The reverse coded self-concept clarity measure ranged from 1 to $6.92, \alpha=0.93$. A sample item is "My beliefs about myself often conflict with one another". Self-esteem ranged from 1 to $7, \alpha=0.93$, with a sample item being "I feel that I have a number of good qualities". Participants answered all above psychological measures on a sevenpoint scale.

Income (i.e., "What is your combined annual household income?") was recorded in ranges (i.e., <30,000; 30,000-39,999; 40,000-49,999; 50,000-59,999; 60,000-69,999; 70,000-79,999; $80,000-89,999 ; 90,000-99,999$; more than 100,000$)$. We used the midpoints of each range (e.g., 35,000; 45,000) and 25,000 for the first and 105,000 for the last category (all divided by 1,000 ) as val- 


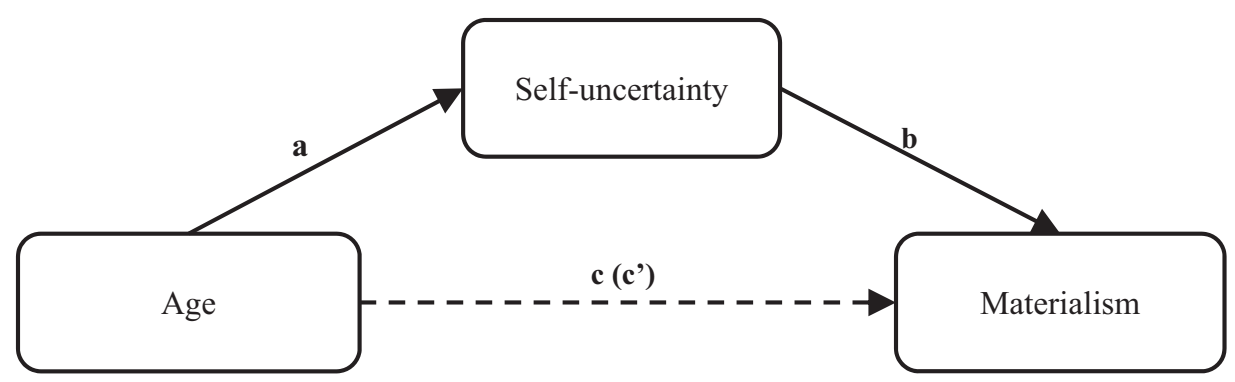

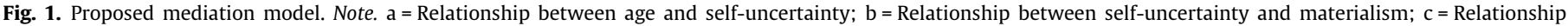
between age and materialism; $c^{\prime}=$ Direct relationship between age and materialism after controlling for the indirect effect via self-uncertainty

ues in our regression models. Whether a participant had a college degree or not was assessed with the following question: "What is the highest level of education you have completed?". Participants were asked to choose from the following categories: "Less than High School", "High School/GED”, "Some College", "2-year College Degree”, "4-year College Degree”, "Masters Degree”, "Doctoral Degree", "Professional Degree (JD, MD)". Categories 1 to 3 were coded as "no college degree", while the remaining categories were coded as "college degree". The data on employment status was based on the open-ended questions "Please indicate your occupation". The first author coded the responses according to the categories used in Jaspers and Pieters (2016).

The sample size was determined by considerations that were related to other projects for which data was collected with this questionnaire. However, according to the power calculator on www.sample-size.net, this study had more than $90 \%$ power to detect a correlation of $r=-0.16$ (i.e., the effect size reported in the meta-analysis by Jaspers \& Pieters, 2016) between age and materialism at the $\mathrm{p}=.05$ level. From our literature review (see Section 1.2), we expected the age-materialism relationship will be the weakest path (i.e., smallest effect size) among all paths in our theoretical model (see Fig. 1). Accordingly, power was greater than $90 \%$ (at the $\mathrm{p}=.05$ level) for all other paths in our theoretical model.

\subsection{Results}

In a first step, we analyzed the correlations between the key concepts of interest in our theoretical model. All measures, with the exception of the self-esteem measure correlated negatively with age (see Table 1 ).

Next, we tested whether the age - materialism relationship can be best captured as a linear relationship in our data. We did this with a set of regression analyses. These regressions all included age and age ${ }^{2}$ as predictors and differed only in the used dependent variables (i.e., our different materialism measures). We did not find an effect of age ${ }^{2}$ on any of our materialism measures (all p >.23). We therefore did not include age ${ }^{2}$ in our main analyses.

After these preliminary analyses, we tested if self-uncertainty (SCC.r) mediates the relation between age and materialism (overall and for each dimension). Following the recommendations of Preacher and Hayes (2008), the indirect effect was tested with the bootstrapping method using 5000 bootstrap samples. The results of these models are included in Table 2. The indirect effect was significant in all four models and self-uncertainty was a mediator in our data.

We reran all models with additional control variables (i.e., gender, education, income, and occupational status) to investigate the robustness of the obtained effects. These additional models (see Table A.1 in the Supplemental Materials) yielded very similar results to those presented in Table 2. The indirect effect is again statistically significant in all models. One difference emerged between the models with and without control variables. The total age - happiness dimension relationship (c path) was not significant (significant) in the model with (without) control variables. The mediation effect however was not altered by this and remained statistically significant.

Last, we tested whether self-esteem could explain the age materialism relationship beyond self-uncertainty. Surprisingly, self-esteem was not related to age in our dataset (see Table 1). However, as mediation can occur even in the absence of a statistically significant relationship between an independent and a mediator variable (Preacher \& Hayes, 2004), we nevertheless tested for mediation. First, we checked for multicollinearity of selfuncertainty and self-esteem. The Variance Inflation Factors (VIFs) indicated that multicollinearity was not a concern (i.e., VIFs $<1.9$ ). We then reran the models reported in Table A.1 in the Supplemental Materials with self-esteem as an additional mediator. Selfesteem was not a significant mediator in any of our models (i.e., $\mathrm{p}>.10$ for all indirect effects involving self-esteem).

Table 1

Means, SDs, and correlation coefficients in Study 1

\begin{tabular}{|c|c|c|c|c|c|c|c|c|}
\hline Variable & $M$ & $S D$ & 1 & 2 & 3 & 4 & 5 & 6 \\
\hline 1. Age & 33.6 & 12.3 & & & & & & \\
\hline 2. MV.overall & 3.8 & 1.2 & $-0.21^{* * *}$ & & & & & \\
\hline 3. MV.success & 3.3 & 1.4 & $-0.23^{* * *}$ & $0.87^{* * *}$ & & & & \\
\hline 4. MV.central & 3.8 & 1.1 & $-0.23^{* * *}$ & $0.82^{* * *}$ & $0.70^{* * * *}$ & & & \\
\hline 5. MV.happy & 4.2 & 1.3 & $-.09^{\mathrm{a}}$ & $0.79^{* * * *}$ & $0.56^{* * *}$ & $0.59^{* * *}$ & & \\
\hline 6. SCC. $\mathrm{r}$ & 3.3 & 1.3 & $-0.21^{* * *}$ & $0.29^{* * *}$ & $0.26^{* * *}$ & $0.22^{* * *}$ & $0.21^{* * *}$ & \\
\hline 7. TSE & 5.2 & 1.3 & 0.05 & $-0.18^{* * *}$ & $-0.15^{* *}$ & $-0.15^{* * *}$ & $-0.25^{* * *}$ & $-0.65^{* * *}$ \\
\hline
\end{tabular}

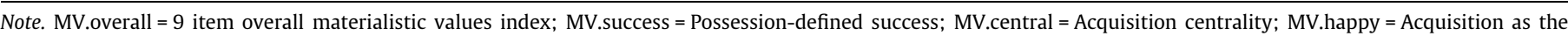
pursuit of happiness; SCC.r = Self-concept clarity (reverse coded); TSE = Trait self-esteem.

${ }^{* * *} \mathrm{p}<.001$

${ }_{* *}^{*} \mathrm{p}<.01$.

$p<.05$.

a $\mathrm{p}=.05$ 
Table 2

Results of the mediation analyses in Study 1.

\begin{tabular}{|c|c|c|c|c|c|c|c|c|}
\hline \multirow[b]{3}{*}{ Path $^{\mathrm{a}}$} & \multirow{2}{*}{\multicolumn{2}{|c|}{ Overall materialism }} & \multicolumn{6}{|c|}{ Materialism facets } \\
\hline & & & \multicolumn{2}{|c|}{ Success } & \multicolumn{2}{|c|}{ Centrality } & \multicolumn{2}{|c|}{ Happiness } \\
\hline & $\beta$ & $\mathrm{p}$ & $\beta$ & $\mathrm{p}$ & $\beta$ & $\mathrm{p}$ & $\beta$ & $\mathrm{p}$ \\
\hline $\mathrm{a}$ & -0.21 & $<0.001$ & -0.21 & $<0.001$ & -0.21 & $<0.001$ & -0.21 & $<0.001$ \\
\hline $\mathrm{b}$ & 0.26 & $<0.001$ & 0.22 & $<0.001$ & 0.18 & $<0.001$ & 0.20 & $<0.001$ \\
\hline c & -0.21 & $<0.001$ & -0.23 & $<0.001$ & -0.23 & $<0.001$ & -0.09 & 0.05 \\
\hline$c^{\prime}$ & -0.16 & $<0.001$ & -0.18 & $<0.001$ & -0.20 & $<0.001$ & -0.05 & 0.28 \\
\hline Indirect effect & -0.05 & $<0.01$ & -0.05 & $<0.01$ & -0.04 & $<0.01$ & -0.04 & $<0.01$ \\
\hline $\mathrm{R}^{2}$ & 0.11 & $<0.001$ & 0.10 & $<0.001$ & 0.09 & $<0.001$ & 0.05 & $<0.001$ \\
\hline
\end{tabular}

Note. Indirect effect tested following Preacher and Hayes' (2008) recommendations and using 5000 bootstrap samples.

a For an explanation of the different paths see Fig. 1.

\subsection{Discussion}

Taken together, the results from Study 1 suggest that selfuncertainty may mediate the effect of age on materialism. These results remained unchanged even after accounting for different socio-demographic characteristics of our participants. It is noteworthy that the mediation effect was somewhat weaker for the centrality dimension than for the other materialism measures in the models with control variables. This is in line with previous findings. In some extant studies, the relationship between selfuncertainty and the centrality dimension appeared to be weaker than those between the other materialism dimensions and selfuncertainty (e.g., Chang \& Arkin, 2002; Noguti \& Bokeyar, 2014).

As opposed to the findings of Jaspers and Pieters (2016), we did not find a quadratic age effect on any of our materialism measures. While this might be surprising at first, a likely explanation could be the composition of our sample. Our sample was noticeably younger (i.e., 33.6 years on average) with a smaller variation in age (i.e., SD $=12.3$ years) compared to Jaspers and Pieters' (2016) participants (i.e., average $=44.6$ years; $\mathrm{SD}=17.2$ years). In the latter study, materialism was found to have a linear negative relationship with age up until the age of 60 . By far most of our participants were younger than 60 years. The age - materialism relationship might therefore be appropriately described as linear in our dataset.

Interestingly, even though the happiness dimension of materialism was not associated with age in the model with controls, the indirect effect was still significant, indicating the potential existence of an opposing process (Zhao, Lynch, \& Chen, 2010). This non-significant effect is similar to some (but not all) effects reported for the happiness dimension in the literature (see Section 4.3 for a more detailed discussion).

Last, our results indicate that self-esteem does not add to the explanation of the age - materialism relationship beyond selfuncertainty. These results have to be interpreted with caution, however. Self-esteem was unexpectedly not related to age. This was surprising because extant literature seems to document changes in self-esteem with age (e.g., Twenge et al., 2017). It is not clear why there was no age - self-esteem relationship in our data. Future research could explore this and study potential moderators of this relationship.

Even though promising, the results from Study 1 are limited in several ways. First, we tested our model in only one population. Second, we used only one type of self-uncertainty in this study. Even though our theory would suggest otherwise, it is possible that the effect is specific to self-concept clarity, while other types of self-uncertainty do not mediate the age - materialism relationship.

\section{Study 2}

The goal of Study 2 was to replicate the findings of Study 1 in a different sample. More importantly, we wanted to investigate whether the proposed mediation effect holds for different types of self-uncertainty.

\subsection{Participants and procedure}

We recruited 547 participants on Crowdflower.com. Two participants were excluded from the final analysis because their age was unclear (i.e., both answered "1" year on the age question), 49 participants were discarded because their answers raised strong doubts as to whether their responses were trustworthy. They used the same answer option (e.g., a "4" for all items) or a fixed pattern (i.e., 7676 and so forth) for all or a great majority of the Likert items in the questionnaire. The final sample consisted of 496 participants ( $45 \%$ male). The mean age was 35.2 years $(S D=12.5$; Range $=18$ 75 years). The median combined annual household income of our participants was in the 50,000-59,999 USD bracket. Fifty-five percent of our participants possessed a college or professional degree, $61 \%$ were currently in a romantic relationship, and $49 \%$ had children. Most participants were employed or self-employed (i.e., $67 \%$ ), $8 \%$ were students, $3 \%$ were retired, $17 \%$ were not currently officially employed, and $6 \%$ did not clearly indicate what their employment status was.

Data for this study was again collected as part of a larger survey. After informed consent was obtained, participants first completed several unrelated tasks before the self-uncertainty measures. After more unrelated measures, participants indicated their relationship status and whether they had children. This was followed by more unrelated measures and tasks. Participants then completed the self-esteem and materialism measures, another unrelated task, and demographics.

Materialism was again measured with the 15-item MVS (Richins, 2004) and self-esteem with Rosenberg's (1965) scale and with Robins, Hendin, and Trzesniewski's (2001) single-item measure. Self-uncertainty was assessed with the SCC and selfdoubt (SeDo; Oleson et al., 2000) scales. All of the psychological measures were answered on a seven-point scale. The actual scores on all materialism measures, as well as both self-esteem measures and the self-doubt measure ranged from 1 to 7 . The reverse scored self-concept clarity measure ranged from 1 to 6.83 . The Cronbach's alphas for the materialism measures were $\alpha_{\text {overall }}=0.87$, $\alpha_{\text {success }}=0.83, \alpha_{\text {centrality }}=0.64$, and $\alpha_{\text {happiness }}=0.80$; for the selfuncertainty measures $\alpha_{\text {Self-concept clarity }}=0.92, \quad \alpha_{\text {Self-doubt }}=0.90$; and for the multi-item self-esteem measure $\alpha=0.93$. Sample items for the self-doubt measure and the single-item self-esteem measure are "When engaged in an important task, most of my thoughts turn to bad things that might happen (e.g., failing) than to good" and "I have high self-esteem", respectively. Sample items for all other measures and sample instructions can be found in Section 3.1.

Relationship status was based on the questions "Are you currently in a romantic relationship?", with answer options "no" 
and "yes". The variable "children" is based on the open-ended question "How many children do you have?". Because we were interested in whether a participant is a parent or not rather than the number of children a participant has, zero children were coded as "no", while any number of children was coded as "yes". All other socio-demographic variables in this study were assessed identically to Study 1 , with one exception. The income question included a reference to USD in Study 2 (i.e., "What is your combined annual household income in USD?").

The sample size decisions were again guided by considerations that were related to other research projects for which we collected data with the same questionnaire. According to www.sample-size. net, we had more than $95 \%$ power to detect an age - materialism relationship of $\mathrm{r}=-0.16$ at the $\mathrm{p}=.05$ level (see Section 3.1 for a more detailed discussion).

\subsection{Results}

Before we tested our theoretical model, we analyzed the correlation between the different constructs of interest (see Table 3). All materialism and all self-uncertainty measures correlated with age in the anticipated direction. Also, all materialism measures correlated with the different self-uncertainty measures.

We again tested whether the relationship between age and materialism can be modeled as a linear relationship. Similar to Study 1 , this was done with regression analyses including age and age $^{2}$ as predictors and the different materialism measures as dependent variables. With the exception of the model in which the success facet was the dependent variable $(p=.07)$, age ${ }^{2}$ did not emerge as a significant predictor in any model (all $\mathrm{p}>.24$ ). The non-linear age effect with regard to the success dimension disappeared when entering gender in the model $(\mathrm{p}=.26)$ and might be explained by a spurious gender-age correlation $(r=-0.19$; $\mathrm{p}<.001$ ) in our sample. Age $^{2}$ was therefore not included in the final mediation analyses.

Next, we tested our theoretical model with the two selfuncertainty variables (i.e., self-concept clarity and self-doubt). The results are displayed in Tables $4 \mathrm{a}$ and $4 \mathrm{~b}$. The proposed mediation is statistically significant in all models with one exception. The indirect effect is only marginally significant in the model with the centrality dimension as a dependent variable and SCC as a measure of self-uncertainty.

We again reran all models with control variables (see Tables B.1a and B.1b in the Supplemental Materials). In these models, all indirect effects reached statistical significance.

Last, we again tested whether self-esteem can explain the age materialism relationship beyond self-uncertainty. The results regarding the single-item self-esteem measure were similar to
Study 1 . This measure was not correlated with age and multicollinearity was not an issue in our data (VIFs < 1.7). All indirect effects through self-esteem as measured with this single item were not statistically significant $(\mathrm{p}>.10)$.

The Rosenberg trait self-esteem measure (TSE) was correlated with age in this dataset. This is in contrast to Study 1 and the findings regarding the single-item measure, but in line with extant literature. Before proceeding with the analyses, we checked for multicollinearity of TSE and our self-uncertainty measures. The VIFs indicate that this was not a concern in our data (all VIFs $<2.6$ ). We therefore proceeded and reran our models (see Tables B.1a and B.1b) with self-esteem as an additional mediator. The inclusion of self-esteem did not alter our results in five out of our eight models (see Tables B.2a and B.2b in the Supplemental Materials). In the model with the centrality dimension as dependent variable, the indirect effect through SCC was not significant after self-esteem was included, even though SCC was significant when it was included as sole mediator. Self-esteem, however, was not a significant mediator in this model either. The inclusion of TSE as an additional mediator had the most noticeable impact in the models with the happiness dimension. Self-esteem emerged as a significant mediator in the model with SCC as an initial mediator, while SCC's indirect effect was no longer significant after TSE was included in the model. In the model with self-doubt, TSE was an additional mediator albeit only marginally significant.

\subsection{Discussion}

The findings from Study 2 are in line with Study 1 and lend further support to our theoretical model. Self-uncertainty again emerged as a mediator between age and materialism and materialism dimensions. This theoretical model was supported across different measures of self-uncertainty and materialism. Moreover, this process appeared to be robust even after controlling for several socio-demographic variables.

Similar to Study 1 , age and self-uncertainty are somewhat less strongly related to the centrality dimensions than to the other two dimensions or overall materialism. As a result, the mediation process through self-uncertainty seems to be stronger for the latter three materialism variables than for the centrality dimension. In fact, in contrast to Study 1, the indirect effect of age on the centrality dimensions through SCC reached only marginal statistical significance when no controls were included. However, it was significant when controls were included and in the models involving self-doubt (SeDo). The marginally significant effect with regard to SCC as a mediator for the relation between age and centrality might therefore be best explained with imprecision in the measurement of the centrality dimension in this study. This would also

Table 3

Means, SDs, and correlation coefficients in Study 2.

\begin{tabular}{|c|c|c|c|c|c|c|c|c|c|c|}
\hline Variable & $M$ & $S D$ & 1 & 2 & 3 & 4 & 5 & 6 & 7 & 8 \\
\hline 1. Age & 35.2 & 12.5 & & & & & & & & \\
\hline 2. MV.overall & 3.9 & 1.2 & $-0.33^{* * * *}$ & & & & & & & \\
\hline 3. MV.success & 3.6 & 1.3 & $-0.35^{* * *}$ & $0.87^{* * *}$ & & & & & & \\
\hline 4. MV.central & 3.7 & 1.0 & $-0.22^{* * *}$ & $0.71^{* * *}$ & $0.56^{* * *}$ & & & & & \\
\hline 5. MV.happy & 4.0 & 1.3 & $-0.23^{* * *}$ & $0.77^{* * * *}$ & $0.52^{* * * *}$ & $0.59^{* * *}$ & & & & \\
\hline 6. SCC.r & 3.5 & 1.3 & $-0.32^{* * *}$ & $0.38^{* * * *}$ & $0.33^{* * * *}$ & $0.16^{* * * *}$ & $0.29^{* * *}$ & & & \\
\hline 7. SeDo & 3.6 & 1.3 & $-0.39^{* * *}$ & $0.42^{* * *}$ & $0.32^{* * *}$ & $0.22^{* * * *}$ & $0.40^{* * * *}$ & $0.73^{* * *}$ & & \\
\hline 8. TSE & 5.0 & 1.3 & $0.31^{* * *}$ & $-0.31^{* * *}$ & $-0.22^{* * * *}$ & $-0.16^{* * *}$ & $-0.37^{* * *}$ & $-0.65^{* * *}$ & $-0.75^{* * * *}$ & \\
\hline 9. SE-SI & 4.6 & 1.7 & 0.03 & -0.03 & $0.11^{*}$ & $-0.15^{* * *}$ & $-0.28^{* * *}$ & $-0.33^{* * * *}$ & $-0.48^{* * * *}$ & $0.63^{* * *}$ \\
\hline
\end{tabular}

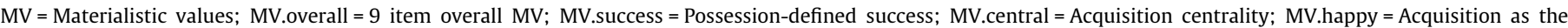
pursuit of happiness; SCC.r = Self-concept clarity (reverse coded); SeDo = Self-doubt; TSE = Trait self-esteem; SE-SI = Single-item self-esteem measure.

$\mathrm{p}<.01$.

$\mathrm{p}<.001$.

$\mathrm{p}<.05$. 
Table 4a

Results of mediation analyses in Study 2 with self-concept clarity as mediator.

\begin{tabular}{|c|c|c|c|c|c|c|c|c|}
\hline \multirow[b]{3}{*}{ Path $^{\mathrm{a}}$} & \multirow{2}{*}{\multicolumn{2}{|c|}{ Overall materialism }} & \multicolumn{6}{|c|}{ Materialism facets } \\
\hline & & & \multicolumn{2}{|c|}{ Success } & \multicolumn{2}{|c|}{ Centrality } & \multicolumn{2}{|c|}{ Happiness } \\
\hline & $\beta$ & $\mathrm{p}$ & $\beta$ & $\mathrm{p}$ & $\beta$ & $\mathrm{p}$ & $\bar{\beta}$ & $\mathrm{p}$ \\
\hline $\mathrm{a}$ & -0.32 & $<0.001$ & -0.32 & $<0.001$ & -0.32 & $<0.001$ & -0.32 & $<0.001$ \\
\hline $\mathrm{b}$ & 0.31 & $<0.001$ & 0.25 & $<0.001$ & 0.10 & 0.03 & 0.24 & $<0.001$ \\
\hline c & -0.33 & $<0.001$ & -0.35 & $<0.001$ & -0.22 & $<0.001$ & -0.23 & $<0.001$ \\
\hline$c^{\prime}$ & -0.23 & $<0.001$ & -0.27 & $<0.001$ & -0.18 & $<0.001$ & -0.15 & $<0.001$ \\
\hline Indirect effect & -0.10 & $<0.01$ & -0.08 & $<0.01$ & -0.03 & $<0.10$ & -0.08 & $<0.01$ \\
\hline $\mathrm{R}^{2}$ & 0.19 & $<0.001$ & 0.18 & $<0.001$ & 0.06 & $<0.001$ & 0.11 & $<0.001$ \\
\hline
\end{tabular}

Note. Indirect effect tested following Preacher and Hayes' (2008) recommendations and using 5000 bootstrap samples.

a For an explanation of the different paths see Fig. 1.

Table 4b

Results of mediation analyses in Study 2 with self-doubt as mediator.

\begin{tabular}{|c|c|c|c|c|c|c|c|c|}
\hline \multirow[b]{3}{*}{ Path $^{\mathrm{a}}$} & \multirow{2}{*}{\multicolumn{2}{|c|}{ Overall materialism }} & \multicolumn{6}{|c|}{ Materialism facets } \\
\hline & & & \multicolumn{2}{|c|}{ Success } & \multicolumn{2}{|c|}{ Centrality } & \multicolumn{2}{|c|}{ Happiness } \\
\hline & $\beta$ & $\mathrm{p}$ & $\beta$ & $\mathrm{p}$ & $\beta$ & $\mathrm{p}$ & $\beta$ & $\mathrm{p}$ \\
\hline $\mathrm{a}$ & -0.39 & $<0.001$ & -0.39 & $<0.001$ & -0.39 & $<0.001$ & -0.39 & $<0.001$ \\
\hline $\mathrm{b}$ & 0.35 & $<0.001$ & 0.21 & $<0.001$ & 0.16 & $<0.001$ & 0.37 & $<0.001$ \\
\hline $\mathrm{c}$ & -0.33 & $<0.001$ & -0.35 & $<0.001$ & -0.22 & $<0.001$ & -0.23 & $<0.001$ \\
\hline $\mathrm{c}^{\prime}$ & -0.19 & $<0.001$ & -0.26 & $<0.001$ & -0.15 & 0.001 & -0.09 & 0.05 \\
\hline Indirect effect & -0.14 & $<0.01$ & -0.08 & $<0.01$ & -0.06 & $<0.01$ & -0.14 & $<0.01$ \\
\hline $\mathrm{R}^{2}$ & 0.21 & $<0.001$ & 0.16 & $<0.001$ & 0.07 & $<0.001$ & 0.17 & $<0.001$ \\
\hline
\end{tabular}

Note. Indirect effect tested following Preacher and Hayes' (2008) recommendations and using 5000 bootstrap samples.

a For an explanation of the different paths see Fig. 1.

be in line with a relatively low coefficient alpha of this materialism dimension.

As in Study 1, age squared did not relate to the materialism measures. A likely explanation for this is again the composition of our sample. Due to the overall age distribution of our sample (i.e., most participants are younger than 60 years), the relationship between age and materialism can arguably be described as linear (see Section 3.3 for a more detailed discussion).

The main difference between the results of Study 1 and 2 pertains to the age - happiness dimension relationship. While the happiness dimension and age were not related in Study 1 after controlling for socio-demographic factors, we observed a negative relationship even when control variables were included in the models in Study 2. This inconsistency is in line with previous literature which sometimes did and sometimes did not find a relationship between age and this materialism dimension (e.g., Jaspers \& Pieters, 2016; Roberts \& Clement, 2007). Because our two studies were conducted using different online platforms (i.e., MTurk and Crowdflower), some unobserved socio-demographic or psychological sample differences may explain this difference between our two studies. Future research could explore the conditions that determine when there is a relation between age and the happiness dimension. Importantly, even though the age - happiness dimension relationships were different in the two samples, Studies 1 and 2 are consistent in supporting self-uncertainty as a mediator between age and the happiness dimension (see also Section 3.3).

Corroborating the results from Study 1, self-esteem again did not emerge as an additional mediating process in most of our models. It however noticeably impacted the results regarding the happiness dimension of materialism. This indicates that there might be merit in including self-esteem in the theoretical model as suggested by Chaplin and John (2007) and Jaspers and Pieters (2016) when studying the happiness dimension of materialism. This is also reinforced by self-esteem correlating most strongly with this dimension in our studies (see Noguti \& Bokeyar, 2014 for a similar finding).

\section{General discussion}

Both studies converge in their support for self-uncertainty as a mediator in the relation between age and materialism. As people grow older, their self-uncertainty decreases, which in turn seems to decrease their level of materialism. Evidence for this mechanism was found in different samples, across different measures of selfuncertainty and materialism, and after controlling for various socio-demographic variables. These studies are noteworthy as they investigate the processes underlying the often reported age materialism relationship in adults.

While materialism is often studied as a single overarching construct, our results suggest that there is merit in a differentiated investigation into different materialism facets (see also Jaspers \& Pieters, 2016). First, even though our model holds for the centrality dimension of materialism, the mediation effect appeared to be weaker for this dimension than for the other materialism facets. This suggests that at least in some cases it might be fruitful to distinguish between the different materialism dimensions in future theorizing and empirical investigations. For example, individuals might perceive that focusing their efforts on acquiring successrelated possessions can function as a remedy for self-uncertainty (e.g., doubt about one's ability; Sivanathan \& Pettit, 2010). If high self-uncertainty individuals can prove to themselves that they have at least some level of success (e.g., through the acquisition of possessions), it might reduce their self-uncertainty. A similar argument could be made for the role of the acquisition of possessions in pursuit of happiness. Self-uncertainty has been related to negative emotional outcomes (e.g., Campbell et al., 1996). Individuals might therefore adopt a mindset that these negative emotions can be dealt with or that they can at least distract themselves from these negative feelings by adopting a mindset that possessions, and the acquisition of possessions, provide them with happiness. A focus on the acquisition of possessions per se with no functional belief attached to possessions (i.e., as indicators of success or sources of happiness), on the other hand, might be somewhat less 
relevant to self-uncertainty and individuals' attempts to cope with elevated levels of self-uncertainty.

Second, even though the mediation process was supported in both studies, the relationship between age and the happiness dimension of materialism differed between Studies 1 and 2 . Future research could investigate if certain socio-demographic or psychological factors can influence how the belief that acquisition is related to happiness changes with age. Third, though this was inconsistent, self-esteem emerged as a mediator between age and possession-defined happiness in some of our models. More consistent, however, was the observation that self-esteem correlated somewhat stronger with the happiness dimension than with the other materialism facets. This again might point to the need to study different materialism dimensions individually and develop a fine-grained theory with regards to different facets of materialism.

The main limitation of our two studies is in their cross-sectional nature. Because of this, we cannot distinguish between age, period, and cohort effects (Yoon et al., 2009). Our theorizing would suggest that the observed mediating mechanism is a life-cycle effect. However, since our data does not allow us to test this, this remains speculative at this stage. Longitudinal studies are necessary to gain further insights into this matter.

Similarly, the cross-sectional nature of our studies does not allow us to investigate causality directly. While age is an exogenous variable (i.e., age is not influenced by self-uncertainty and materialism), the directionality of the self-uncertainty and materialism relationship cannot be studied with our data. In other words, our data cannot give a definitive answer to the question whether changes in self-uncertainty indeed cause changes in materialism or whether the opposite is the case. Our theorizing and previous literature suggest that self-uncertainty is an antecedent to materialism (e.g., Kasser, 2016). However, there might be a feedback loop as well. It could be that materialistic goals and behavior may increase self-uncertainty in certain individuals. Future research could use longitudinal study designs to investigate the causal relationships in our theoretical model and the potential presence of feedback loops.

In addition, it is not clear whether our findings generalize to offline populations. While our studies utilized online populations, we have no reason to believe that samples collected in an offline environment would differ in the investigated process. However, future research could investigate this. Lastly, our sample consisted of individuals from Western societies due to the data collection platforms used. Future research could investigate whether our theoretical model can be replicated in Asian or African samples as well. Our intuition is that it will be possible to replicate the effect albeit its strength might vary. As discussed earlier, Jaspers and Pieters (2016) reported in their meta-analysis that age and materialism were associated in samples from different countries. Though, there was considerable variation in the strength of this correlation between countries.

\section{Conclusions}

Overall, the present research makes an important contribution to the literature by identifying one mechanism that seems to link age and materialism. Researchers could build on our findings and study additional mediators and moderating mechanisms of the age - materialism relationship. We believe that there is still much to be learned about this relationship. Given the many detrimental consequences of materialism in society, a better understanding of this relationship may help policy makers who wish to reduce materialistic tendencies in society.

\section{Acknowledgements}

This work was supported by a grant from the HEC Research Fund for Doctoral Students and Post Docs of the University of Lausanne. The HEC Research Fund for Doctoral Students and Post Docs was not involved in the reported research project other than by providing funding for Study 1.

\section{Declaration of interest}

None.

\section{Appendix A. Supplementary material}

Supplementary data to this article can be found online at https://doi.org/10.1016/j.jrp.2018.09.007.

\section{References}

Belk, R. W. (1985). Materialism: Trait aspects of living in the material world. Journal of Consumer Research, 12(3), 265-280.

Braslow, M. D., Guerrettaz, J., Arkin, R. M., \& Oleson, K. C. (2012). Self-doubt. Social and Personality Psychology Compass, 6(6), 470-482.

Campbell, J. D., Trapnell, P. D., Heine, S. J., Katz, I. M., Lavallee, L. F., \& Lehman, D. R. (1996). Self-concept clarity: Measurement, personality correlates, and cultural boundaries. Journal of Personality and Social Psychology, 70(1), 141-156.

Chang, L., \& Arkin, R. M. (2002). Materialism as an attempt to cope with uncertainty. Psychology \& Marketing, 19(5), 389-406.

Chaplin, L. N., \& John, D. R. (2007). Growing up in a material world: Age differences in materialism in children and adolescents. Journal of Consumer Research, 34(4), 480-493.

Christopher, A. N., Drummond, K., Jones, J. R., Marek, P., \& Therriault, K. M. (2006) Beliefs about one's own death, personal insecurity, and materialism. Personality and Individual Differences, 40(3), 441-451.

Crocetti, E., Rubini, M., Branje, S., Koot, H. M., \& Meeus, W. (2016). Self-concept clarity in adolescents and parents: A six-wave longitudinal and multi-informant study on development and intergenerational transmission. Journal of Personality, 84(5), 580-593.

De Cremer, D. \& Sedikides, C. (2005). Self-uncertainty and responsiveness to procedural justice. Journal of Experimental Social Psychology, 41(2), 157-173.

Dittmar, H. (2005). Compulsive buying - A growing concern? An examination of gender, age, and endorsement of materialistic values as predictors. British Journal of Psychology, 96(4), 467-491.

Dittmar, H., Bond, R., Hurst, M., \& Kasser, T. (2014). The relationship between materialism and personal well-being: A meta-analysis. Journal of Personality and Social Psychology, 107(5), 879-924.

Duh, H. I. (2016). Childhood family experiences and young Generation Y money attitudes and materialism. Personality and Individual Differences, 95, 134-139.

Goldberg, M. E., Gorn, G. J., Peracchio, L. A., \& Bamossy, G. (2003). Understanding materialism among youth. Journal of Consumer Psychology, 13(3), 278-288.

Hui, C., \& Tsang, O. (2017). The role of materialism in self-disclosure within close relationships. Personality and Individual Differences, 111, 174-177.

Hurst, M., Dittmar, H., Bond, R., \& Kasser, T. (2013). The relationship between materialistic values and environmental attitudes and behaviors: A metaanalysis. Journal of Environmental Psychology, 36, 257-269.

Jaspers, E. D. T., \& Pieters, R. G. M. (2016). Materialism across the life span: An ageperiod-cohort analysis. Journal of Personality and Social Psychology, 111(3), $451-473$.

Kasser, T. (2016). Materialistic values and goals. Annual Review of Psychology, 67, 489-514.

Kasser, T., Rosenblum, K. L., Sameroff, A. J., Deci, E. L., Niemiec, C. P., ... Ryan, R. M. et al. (2014). Changes in materialism, changes in psychological well-being: Evidence from three longitudinal studies and an intervention experiment. Motivation and Emotion, 38(1), 1-22.

Kasser, T., Ryan, R. M., Couchman, C. E., \& Sheldon, K. M. (2004). Materialistic values: Their causes and consequences. In T. Kasser \& Allen D. Kanner (Eds.), Psychology and consumer culture: The struggle for a good life in a materialistic world (pp. 11-28). Washington, DC: American Psychological Association.

Lodi-Smith, J., \& Roberts, B. W. (2010). Getting to know me: Social role experiences and age differences in self-concept clarity during adulthood. Journal of Personality, 78(5), 1383-1410.

Lodi-Smith, J., Spain, S. M., Cologgi, K., \& Roberts, B. W. (2017). Development of identity clarity and content in adulthood. Journal of Personality and Social Psychology, 112(5), 755-768.

Meier, L. L., Orth, U., Denissen, J. J., \& Kühnel, A. (2011). Age differences in instability, contingency, and level of self-esteem across the life span. Journal of Research in Personality, 45(6), 604-612. 
Müller, A., Smits, D. J., Claes, L., Gefeller, O., Hinz, A., \& de Zwaan, M. (2013). The German version of the material values scale. GMS Psycho-Social-Medicine, 10.

Muñiz-Velázquez, J. A., Gomez-Baya, D., \& Lopez-Casquete, M. (2017). Implicit and explicit assessment of materialism: Associations with happiness and depression. Personality and Individual Differences, 116, 123-132.

Noguti, V., \& Bokeyar, A. L. (2014). Who am I? The relationship between selfconcept uncertainty and materialism. International Journal of Psychology, 49(5), 323-333.

Oleson, K. C., Poehlmann, K. M., Yost, J. H., Lynch, M. E., \& Arkin, R. M. (2000). Subjective overachievement: Individual differences in self-doubt and concern with performance. Journal of Personality, 68(3), 491-524.

Opree, S. J., Buijzen, M., van Reijmersdal, E. A., \& Valkenburg, P. M. (2014). Children's advertising exposure, advertised product desire, and materialism: A longitudinal study. Communication Research, 41(5), 717-735.

Orth, U., Trzesniewski, K. H., \& Robins, R. W. (2010). Self-esteem development from young adulthood to old age: A cohort-sequential longitudinal study. Journal of Personality and Social Psychology, 98(4), 645-658.

Otero-López, J. M., Pol, E. V., Bolaño, C. C., \& Mariño, M. J. S. (2011). Materialism, lifesatisfaction and addictive buying: Examining the causal relationships. Personality and Individual Differences, 50(6), 772-776.

Otero-López, J. M., \& Villardefrancos, E. (2013). Five-factor model personality traits, materialism, and excessive buying: A mediational analysis. Personality and Individual Differences, 54(6), 767-772.

Park, J. K., \& John, D. R. (2011). More than meets the eye: The influence of implicit and explicit self-esteem on materialism. Journal of Consumer Psychology, 21(1), $73-87$.

Preacher, K. J., \& Hayes, A. F. (2004). SPSS and SAS procedures for estimating indirect effects in simple mediation models. Behavior Research Methods, 36(4), 717-731.

Preacher, K. J., \& Hayes, A. F. (2008). Asymptotic and resampling strategies for assessing and comparing indirect effects in multiple mediator models. Behavior Research Methods, 40(3), 879-891.

Reeves, R. A., Baker, G. A., \& Truluck, C. S. (2012). Celebrity worship, materialism, compulsive buying, and the empty self. Psychology \& Marketing, 29(9), 674-679.

Richins, M. L. (2004). The material values scale: Measurement properties and development of a short form. Journal of Consumer Research, 31(1), 209-219.

Richins, M. L., \& Chaplin, L. N. (2015). Material parenting: How the use of goods in parenting fosters materialism in the next generation. Journal of Consumer Research, 41(6), 1333-1357.

Richins, M. L., \& Dawson, S. (1992). A consumer values orientation for materialism and its measurement: Scale development and validation. Journal of Consumer Research, 19(3), 303-316.
Rindfleisch, A., Burroughs, J. E., \& Denton, F. (1997). Family structure, materialism, and compulsive consumption. Journal of Consumer Research, 23(4), 312-325.

Rindfleisch, A., Burroughs, J. E., \& Wong, N. (2009). The safety of objects: Materialism, existential insecurity, and brand connection. Journal of Consumer Research, 36(1), 1-16.

Roberts, J. A., \& Clement, A. (2007). Materialism and satisfaction with over-all quality of life and eight life domains. Social Indicators Research, 82(1), 79-92.

Robins, R. W., Hendin, H. M., \& Trzesniewski, K. H. (2001). Measuring global selfesteem: Construct validation of a single-item measure and the Rosenberg SelfEsteem Scale. Personality and Social Psychology Bulletin, 27(2), 151-161.

Rosenberg, M. (1965). Society and the adolescent child. Princeton, NJ: Princeton University Press.

Ruvio, A., Somer, E., \& Rindfleisch, A. (2014). When bad gets worse: The amplifying effect of materialism on traumatic stress and maladaptive consumption. Journal of the Academy of Marketing Science, 42(1), 90-101.

Shrum, L. J., Wong, N., Arif, F., Chugani, S., Gunz, A., Lowrey, T. M., ... Sundie, J. (2013). Reconceptualizing materialism as identity goal pursuits: Functions, processes, and consequences. Journal of Business Research, 66(8), 1179-1185.

Sivanathan, N. \& Pettit, N. C. (2010). Protecting the self through consumption: Status goods as affirmational commodities. Journal of Experimental Social Psychology, 46(3), 564-570.

Twenge, J. M., Carter, N. T., \& Campbell, W. K. (2017). Age, time period, and birth cohort differences in self-esteem: Reexamining a cohort-sequential longitudinal study. Journal of Personality and Social Psychology, 112(5) e9-e17.

Twenge, J. M., \& Kasser, T. (2013) Generational changes in materialism and work centrality, 1976-2007: Associations with temporal changes in societal insecurity and materialistic role modeling. Personality and Social Psychology Bulletin, 39(7), 883-897.

Wang, G., Liu, L., Tan, X., \& Zheng, W. (2017). The moderating effect of dispositiona mindfulness on the relationship between materialism and mental health. Personality and Individual Differences, 107, 131-136.

Wang, J., \& Wallendorf, M. (2006). Materialism, status signaling, and product satisfaction. Journal of the Academy of Marketing Science, 34(4), 494-505.

Yoon, C., Cole, C. A., \& Lee, M. P. (2009). Consumer decision making and aging: Current knowledge and future directions. Journal of Consumer Psychology, 19(1) $2-16$.

Zhao, X., Lynch, J. G., \& Chen, Q. (2010). Reconsidering Baron and Kenny: Myths and truths about mediation analysis. Journal of Consumer Research, 37(2), 197-206. 